\title{
REDUCTION OF TOXIC ELEMENT MOBILITY IN MINING SOIL BY ZEOLITIC AMENDMENTS
}

\author{
Giannatou S. ${ }^{1}$, Vasilatos Ch. ${ }^{1}$, Mitsis I. ${ }^{1}$, Koukouzas N. ${ }^{2}$, Itskos G. ${ }^{3}$ and \\ Stamatakis G.M. ${ }^{1}$ \\ ${ }^{1}$ Department of Geology and Geoenvironment, National \& Kapodistrian University of Athens, \\ Panepistimiopolis, Ano Ilissia, GR-15784, Athens, Greece, spiridoula_14@hotmail.com \\ ${ }^{2}$ Centre for Research and Technology Hellas, Chemical Process and Energy Resources Institute, \\ 52 Egialias str., GR-151 25, Maroussi, Athens, Greece, koukouzas@certh.gr \\ ${ }^{3}$ Nazarbayev University, School of Engineering, 53 Kabanbay batyr ave., Astana, 010000, \\ Republic of Kazakhstan, gregoryitskos@gmail.com
}

\begin{abstract}
The aim of this study is to examine the effectiveness of natural and synthetic zeolitic materials as potential amendments for the rehabilitation of mine degraded areas. Two types of natural zeolite tuffs, clinoptilolite- and mordenite-rich originating from Samos Island, Greece, were used as low cost modifiers. In addition, the synthetic zeolite Na-P1, produced from lignite fly ash of the Meliti Lignite fired Power Station (Florina, Greece), was used. Fly ash was converted into synthetic zeolite via a low temperature alkaline hydrothermal treatment. In order to evaluate the aquatic solubility and potential bioavailability of heavy metals in contaminated soils of the mining area of Lavrion, specific soil amendments were used in leaching experiments. The Na-Plzeolite proved to be the most effective among the tested amendments for in situ de-contamination of mining soils. Comparing the two natural zeolites used, the mordenite-rich tuff exhibited better results than the clinoptilolite-rich, for the reduction of the potential bioavailability of almost all the studied heavy metals. Despite the high trace element content of the specific soils, it was observed that the Glaucium flavum, a plant that grows in the contaminated soils of Lavrion, does not accumulate high concentrations of metals; therefore the high toxic element content of soils does not always influence the physiology of the plants.
\end{abstract}

Keywords: Contaminated soils, synthetic zeolite, fly ash, leaching, bioavailability.

\section{Introduction}

A significant problem in mining areas is the local pollution of the soil close to the mining or dumping area with hazardous heavy metals and metaloids. In general, soils have the natural capacity to mitigate the bioavailability and mobility of metals through mechanisms of precipitation, adsorption processes and/or redox reactions (Vasilatos et al., 2015). Nevertheless, when the concentration of heavy metals is significantly increased, soil's capacity to mobilize the contaminants becomes limited. Thus, there is a contamination risk of agricultural lands, vegetation, and/or groundwater. A notorious example of local but extremely contaminated area is the Lavrion region, Attica Greece, where mining activities had been taking place from antiquity up until the $20^{\text {th }}$ century. Besides fluorite that was extracted for its use as flux in the cement industry in the ' 70 s, the major metals 
extracted from Lavrion were lead, silver and zinc. These metals derived from the mining and metallurgical processing of sulfide ores (Ag-bearing galena, sphalerite and arsenopyrite) of the area. Those activities had produced over the centuries a vast amount of tailings that were generally deposited upon the soil surface in forms of smelting waste, slags, sulfur compounds, etc., all rich in hazardous metals and metalloids. These kinds of tailings usually provide an unfavorable substrate for plant growth because of their low $\mathrm{pH}$, high concentrations of toxic elements and low nutrient content (Ha et al., 2011). Specifically, mining, processing and dumping of wastes, in several cases have produced severe heavy element pollution (Baker et al., 1994). Heavy metals are generally immutable, non-degradable and persistent in soils, unlike any organic contaminants (Adriano et al., 2004; Shi et al., 2009; Sunarso and Ismadji, 2009 and Peng et al., 2009). Consequently, it's necessary to take action in order to remediate heavily polluted soils. For the stabilization of contaminated soils, a variety of methods have been suggested and developed. However, soil cleanup technologies are often expensive, energy consuming and usually soil can rarely be used after the treatment. Moreover, the economic limitations related to the removal of the contaminated soil and its ex-situ treatment have led to a closer investigation of potential in-situ treatment techniques including stabilization/solidification processes. Those techniques usually involve mixing of the contaminated soil or waste in situ with appropriate amendments and curing for the reactions to proceed (Conner, 1990). Many stabilization techniques including the application of lime, cement, coal fly ash and phosphates among other natural and synthetic additives employing various fixation mechanisms, have been tested in mining soils with varying degrees of contamination (Stouraiti et al., 2002 and Martinez-Sanchez et al., 2011).

Zeolite tuffs have been extensively studied for their potential use as remediation agents in contaminated soils, soil amendments and as substrates in hydroponics (e.g. Stamatakis et al., 2001; Savvas et al., 2004; Castaldi et al., 2005; Filippidis and Kantiranis, 2005; Kumpiene et al., 2008 and Fillipidis, 2010). Zeolite is a group of porous aluminosilicate minerals with a negative charge, having a three-dimensional framework, neutralized by introducing exchangeable cations in their crystal structure. The ion exchanging efficiency depends on the micro-porosity and mineral structure of each particular zeolitic type. Moreover, it has been referred that zeolites may be more suitable for rehabilitation of heavy metal-contaminated soils than other amendments, because of their property to regulate modestly soil's $\mathrm{pH}$ and do not import any new pollutants (Castaldi et al., 2005 and Kumpiene et al., 2008).

The idea of utilizing the coal (with a broad sense, including lignite) fly ash as a low-cost sorbent for the removal of heavy metals (e.g. Srivastava et al., 2006; Pehlivan et al., 2006; Itskos et al., 2010 and Alexopoulos et al., 2013), radionuclides, and organic pollutants as well (e.g. Sun et al., 2010; Karagozoglu et al., 2007 and Janos et al., 2003), has been extensively discussed. Even though raw coal fly ashes usually have low sorption capacity, physical and/or chemical modifications have often been examined for their enhancement. Coal fly ash is a suitable material for zeolite synthesis, when it is of aluminosilicate composition.

The fly ash low temperature hydrothermal zeolitization processes implemented in the present study, are based on the chemical attack of Al-Si bearing phases of the fly ash by alkaline solutions and the subsequent transformation to zeolitic material (Querol et al., 2002; Mouhtaris et al., 2003; Koukouzas et al., 2010 and Itskos et al., 2015). Products of such transformation have been described by better ion-exchange properties and several fold-enlarged surfaces (Remenarova et al., 2014 and Giannatou et al., 2015).

The current study deals with the evaluation of water solubility and potential bioavailability of heavy metals in the Lavrion contaminated soil, after its amendment with natural and synthetic zeolitic materials. In addition, Glaucium flavum, a plant species, which grows naturally in Lavrion highly contaminated soils was sampled and analyzed in order to determine its heavy metal accumulation capability and investigate if it could be used in bio-remediation processes. 


\section{Materials and Methods}

The laboratory tests were performed at the Economic Geology and Geochemistry Laboratory of National and Kapodistrian University of Athens. The mineralogical composition of the materials used was identified by X-ray diffraction (XRD) analysis on a Bruker Model 5005 X-ray diffractometer in combination with the DIFFRACplus software package. The diffractometer was operated using $\mathrm{Cu} \mathrm{K}-\mathrm{a}$ radiation at $40 \mathrm{kV}$ and $40 \mathrm{~mA}$, with graphite monochromator, and employing the following scanning parameters: $0.020^{\circ}$ step size and $2.0 \mathrm{sec}$. step time. The output files were evaluated for mineralogical identifications by the EVA 10.0 program of the Bruker DIFFRACplus software package. The measurement of $\mathrm{pH}$ in the solid samples was performed by dilution of the solid in dionized water at a ratio of 1:1 solid:liquid. Then, the Consort 561 multimeter was used for the $\mathrm{pH}$ determination.

Natural and synthetic zeolitic materials were used as amendments in contaminated soils from an abandoned mine site. The natural zeolites used, clinoptilolite-rich tuff (ZCS) and mordenite-rich tuff (ZMS), originated from Samos Island, Greece. Clinoptilolite is widely used in several applications worldwide. The porous structure of clinoptilolite has a heterogeneous nature and is classified as sorbent. Several authors classified it in heulandite family (Breck, 1974), but its Si/Al ratio and thermal stability is different than heulandites (Mansouri et al., 2013). On the other hand, mordenite from the Late Miocene rhyolitic tuffs of Samos is remarkably rich in K and depleted in Na. The needle-like mordenite crystals drapes across smectite; other silica mineral such as quartz and cristobalite are also present. The use of mordenite type zeolite rocks is an ambiguous issue, as in some countries it is classified as fibrous mineral (e.g. Suzouki, 1982 and Spurny, 1983), while in others is used extensively in construction and environmental applications (i.e. Hungary, Romania, Japan, Australia and Philippines). The lignite fly ash sample (CFA) used, derived from the electrostatic precipitators of the lignite-fired Meliti Power Station (Florina, Greece). The CFA was converted to synthetic zeolitic material (FAZ) via a low temperature alkaline hydrothermal treatment with $1 \mathrm{M} \mathrm{NaOH}$. The hydrothermal treatment, proposed by Koukouzas et al. (2010) and Itskos et al. (2015) took place at $90-100^{\circ} \mathrm{C}$. The zeolite produced was $\mathrm{Na}-\mathrm{P} 1\left(\mathrm{Na}_{6} \mathrm{Al}_{6} \mathrm{Si}_{10} \mathrm{O}_{32} \cdot 12 \mathrm{H}_{2} \mathrm{O}\right)$, a synthetic mineral with high ion exchange capacity due to the substitution of $\mathrm{Si}$ (IV) by $\mathrm{Al}$ (III) in its structure, which results in an increased overall negative charge. Heavily contaminated soil samples (LSoil) were collected near the Lavrion harbor, (Figure 1). The soil samples were air dried for 5-6 days.

In order to evaluate the effectiveness of natural and synthetic zeolitic materials as amendments to reduce the solubility and potential bioavailability of heavy metals in the contaminated soil, the following experiment was conducted: a quantity of $4 \mathrm{~kg}$ of contaminated soil and each amendment (ZCS, ZMS and FAZ) at a rate of $10 \%$ by weight was used, to produce the CLS, MLS and FLS soil mixtures accordingly. The mixtures were equilibrated for 1 week, moistened to $40 \%$ of their water holding capacity. Control pots without any amendment (Control) were also set up. All treatments in the experiment were replicated 3 times. The experiment lasted ten weeks under natural environmental conditions. The moisture was maintained throughout the ten weeks by irrigation twice a week. Afterwards a compliance test for leaching of heavy metals was conducted in the soil treatments. According to the European Standard 12457-2, the solid matter and distilled water were placed in a bottle at a liquid to solid ratio of $10 \mathrm{l} / \mathrm{kg}$. The bottle was agitated for $24 \mathrm{~h}$ and the suspended solids were let to settle for $15 \mathrm{~min}$. Filtration of the eluate followed and the metals in the leachates were analyzed with a Perkin Elmer $1100 \mathrm{~b}$ atomic absorption spectrophotometer (AAS). The potential bioavailable fraction was determined by leaching with $0,05 \mathrm{~N}$ EDTA (ethylenediaminetetraacetic acid, $\mathrm{C}_{10} \mathrm{H}_{16} \mathrm{~N}_{2} \mathrm{O}_{8}$ ). Five grams of each solid sample were mixed with $25 \mathrm{ml}$ of extraction solution in a $50 \mathrm{ml}$ flask and the slurry was agitated for $1 \mathrm{~h}$ at $150 \mathrm{rpm}$. Following the filtration of the slurries, the metals in the leachates were analyzed by the AAS method. 


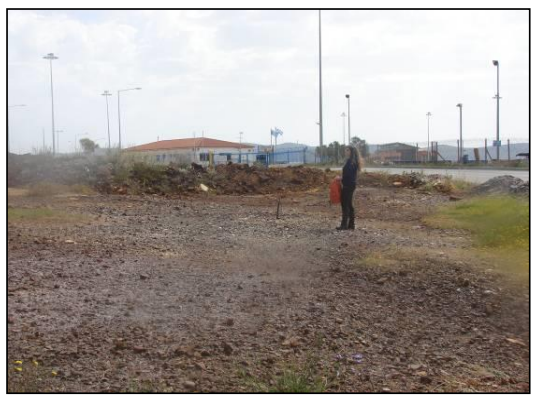

Figure 1 -

Contaminated soil sampling in Lav rion area.

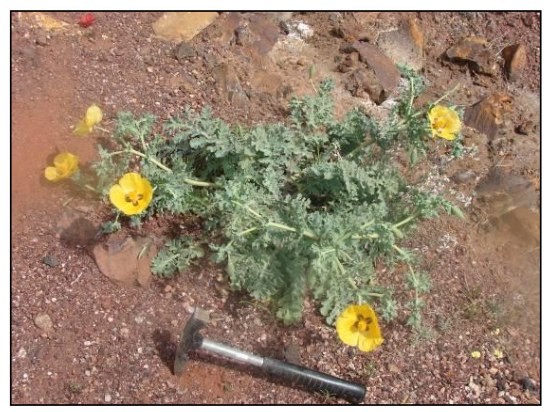

Figure 2 -

The Glaucium flavum plant grows naturally in the s ampling area.

During this study, plant species of Glaucium flavum were sampled from the same area of Lavrion (Figure 2). Plant samples, were separated into root and above-ground (flower and shoots and leaves) biomass and then lyophilized. $0,5 \mathrm{~g}$ of the lyophilized plant tissue were placed in Teflon vessels with $1 \mathrm{ml}$ of $30 \% \mathrm{H} 2 \mathrm{O} 2$ (perhydrol) and $6 \mathrm{ml}$ of concentrated HNO3 acid solution. When digestion was complete (25 minutes at $1000 \mathrm{~W}$ in an ETHOS 1600 MILESTONE Microwave System), the samples were left to cool and then transferred to a volumetric flask to a final volume of $100 \mathrm{~mL}$ with distilled water. $\mathrm{Cd}, \mathrm{Pb}, \mathrm{Zn}, \mathrm{Cu}, \mathrm{Mn}$ and $\mathrm{Fe}$ content were determined by the AAS method.

\section{Results}

The mineralogical composition of both natural and synthetic zeolitic materials used, is presented in Table 1. These results for the natural zeolitic tuffs are in accordance with those reported by Filippidis et al., 2007, (ZCS may contain approx. $60 \mathrm{wt} \%$ clinoptilolite and ZMS may contain 21-64 wt\% mordenite). The high degree of zeolitization of the lignite fly ash (CFA) after the alkaline hydrothermal treatment is demonstrated in the XRD patterns (Figure 3). While the CFA (upper pattern in blue) consists mainly of quartz and feldspar, the synthetic zeolite (FAZ) (bottom pattern in black) consists mainly of Na-P1 zeolite. The specific zeolite has an affinity with the cations that are generally found in acid mine drainage effluents (Cardoso et al., 2015). The pH values of all materials used are presented in Table 2. The synthetic zeolitic material exhibits higher $\mathrm{pH}$ values in comparison to the natural zeolites samples. As expected, the untreated contaminated soil from Lavrion (LSoil) has acidic [3.82] $\mathrm{pH}$ value. The untreated soil sample (Control), had a $\mathrm{pH}$ value as low as 4.52 , after the equilibration.

The amended soil mixtures have showed an increased $\mathrm{pH}$. This was particularly evident in FLS sample (amended with synthetic zeolite) that had the highest $\mathrm{pH}$ value but close to MLS $\mathrm{pH}$ value that goes after. The $\mathrm{pH}$ value of the FLS is attributed to the high $\mathrm{pH}$ of the FAZ component used in the mixture. It is noted that Control sample $\mathrm{pH}$ that has the same composition with LSoil, presents higher values after the equilibration. In Table 3 is illustrated that the concentrations of heavy metals in water leachat of amended soil samples were lower than those of the untreated soil sample (Control). Among the soil treatments the FLS one (amended with synthetic zeolite) exhibited the lowest concentrations for all studied heavy metals.

The potential bioavailability of heavy metals expressed with EDTA values (Table 3), exhibited higher values as expected.

The EDTA buffers a lower soil $\mathrm{pH}$ and, consequently, a higher percentage of the heavy metals content of the soil may be mobilized to the leachates. Between the two natural zeolites, MLS sample (amended with Mordenite-rich material) had better performance excibiting lower potential bioavailability for all the heavy metals, compared to the Control. On the other hand, the synthetic zeolitic amended FLS, exhibited lower potential bioavailability for $\mathrm{Cd}, \mathrm{Cu}, \mathrm{Mn}$ and $\mathrm{Fe}$. Moreover, 
the concentration of heavy metals in different parts of Glaucium flavum is presented in Table 4. The root exhibited the highest values for all heavy metals, in contrast with the flower which had the lowest values.

Table 1 - Mineralogical composition of the zeolitic materials (+: presence of mineral, -: absence of mineral, MJ: Major mineral phase).

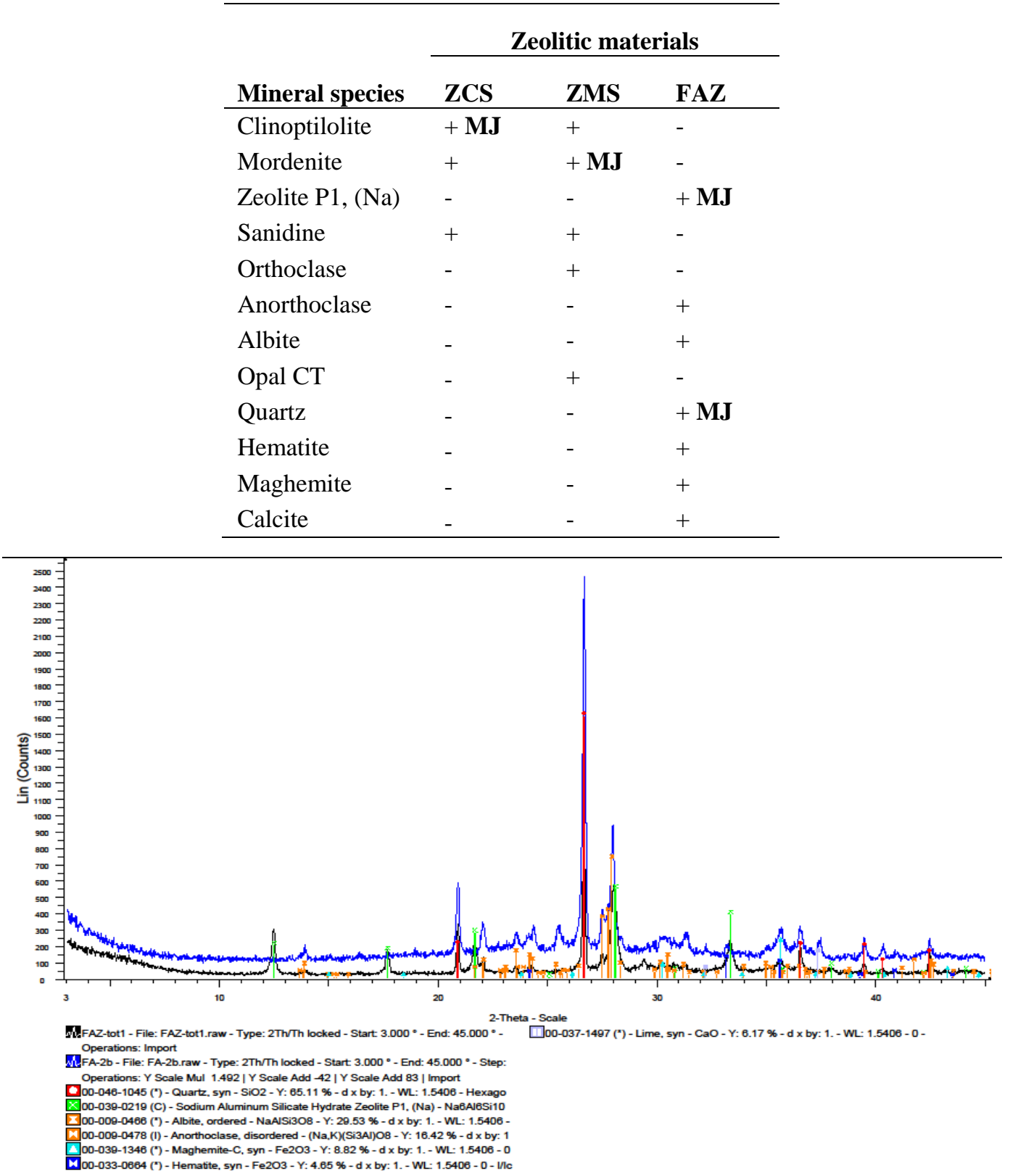

Figure 3 - XRD patterns of the materials used. The upper pattern (in blue) is from the coal fly ash (CFA) before the alkaline hydrothermal treatment and the lower (in black) is from the synthetic zeolite rich material (FAZ) after the treatment. 
Table 2 - pH values of natural and synthetic zeolitic materials, along with the contaminated soil sample and soil treatments after the 10 weeks experimental period.

\begin{tabular}{lcll}
\hline $\begin{array}{l}\text { Soil \& zeolitic amen } \\
\text { dments }\end{array}$ & $\mathbf{p H}$ & $\begin{array}{l}\text { Soil Treat } \\
\text { ments }\end{array}$ & $\mathbf{p H}$ \\
\hline Lsoil & 3.82 & Control & 4.52 \\
ZCS & 8.18 & CLS & 4.94 \\
ZMS & 7.55 & MLS & 5.38 \\
FAZ & 12.25 & FLS & 5.62 \\
\hline
\end{tabular}

Table 3 - Concentration of heavy metals in soil $(\mu \mathrm{g} / \mathrm{g})$ and in the leachates $(\mu \mathrm{g} / \mathrm{ml})$ after leaching with water and EDTA.

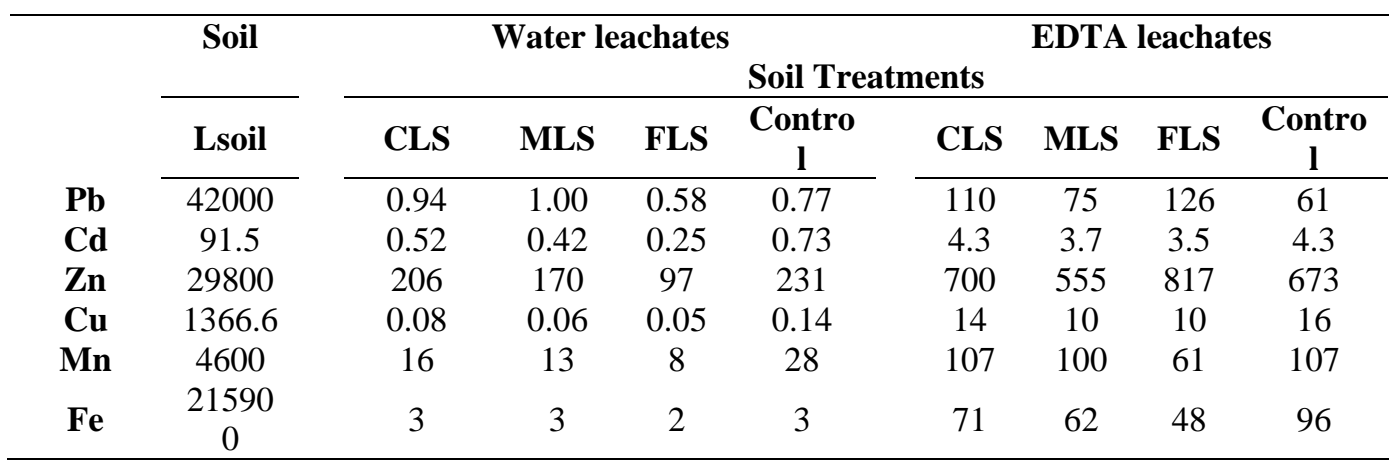

Table 4 - Concentration ( $\mu \mathrm{g} / \mathrm{gr}$ in dry basis) and bio-concentration factor (BCF), of heavy metals in Glaucium flavum.

\begin{tabular}{ccccc}
\hline & \multicolumn{3}{c}{ Plant parts } & BCF \\
\cline { 2 - 4 } & Flower & $\begin{array}{c}\text { Shoots \& } \\
\text { Leaves }\end{array}$ & Root & \\
\hline Pb & 82 & 246 & 887 & 0.02 \\
Cd & $<0.5$ & 8 & 18 & 0.19 \\
Zn & 337 & 1250 & 1720 & 0.06 \\
Cu & 38 & 35 & 84 & 0.06 \\
Mn & 66 & 205 & 227 & 0.05 \\
Fe & 357 & 978 & 3740 & 0.02 \\
\hline
\end{tabular}

\section{Discussion}

A comparative presentation of the effect of natural and synthetic zeolitic amendments to the solubility of the studied heavy metals in the contaminated soil is illustrated in Figure 4. It is evident that the FLS treatment presented reduced solubility of all studied metals ( $\mathrm{Pd}, \mathrm{Cd}, \mathrm{Zn}, \mathrm{Cu}$ and $\mathrm{Mn}$ ) except Fe. The negative effectiveness for $\mathrm{Pb}$ and $\mathrm{Fe}$ may be attributed to their release from the original amendments, as they exhibited high content of these metals (ZCS: $70.5 \mu \mathrm{g} / \mathrm{g} \mathrm{Pb}, 1.3 \% \mathrm{Fe}$, ZMS: $57.3 \mu \mathrm{g} / \mathrm{g} \mathrm{Pb}, 0.8 \%$ $\mathrm{Fe}, \mathrm{FAZ}: 13.6 \mu \mathrm{g} / \mathrm{g} \mathrm{Pb}, 4.7 \% \mathrm{Fe}$ ), in combination with their $\mathrm{pH}$ (Table 2). Among the natural zeolites, the mordenite exhibited better effect in the reduction of the solubility of heavy metals. The crystal structure of zeolite grains constitutes the primary porosity (microporosity) of zeolites, while the grain 
sizes of zeolite and other minerals in the zeolite rocks are connected with the secondary porosity (mesoporosity and macroporosity) (Sprynskyy et al., 2010). The primary porosity is defined as the microporosity displayed by the mineral 3-dimensional alumino-silicate framework. The mesoporosity is formed by slot pores determined mainly by cleavability of the zeolite crystals. The macropores consist of pores of various forms which are located between blocks of the zeolite crystallite and other minerals in the zeolite bearing rocks. For example, the heterogeneity of the clinoptilolite bearing rocks porosity is caused by the presence of associated minerals (albite, mordenite, etc.) and heterogeneity of crystalline structure of those minerals (Mansouri et al., 2013). The mesopores are active surfaces for catalysis, transport channels and adsorption of relatively large molecules. Besides some technological properties which may not be explained by adsorption in micropores, they might be explained by secondary porosity (Mansouri et al., 2013). Moreover, zeolite soil amendments in mining areas may provide sufficient alkalinity to neutralize the acid polluted soils, causing the precipitation of insoluble phases (Chen et al., 2000). The newly formed phases may accommodate the metal pollutants either as major constituents (Chen et al., 2000) or as minor components co-precipitated in hydroxides (Chlopecka and Adriano, 1997 and Boisson et al., 1999). The increase of alkalinity enhances the metal sorption via surface complexation processes. Although mineral surfaces have a positive charge at low $\mathrm{pH}$ values due to the sorption of protons, as $\mathrm{pH}$ increases owing to the deprotonation of the surface unsaturated bonds, they acquire a negative charge (e.g. Basaldella et al., 2007; Peng et al., 2009; Shi et al., 2009). The complexion of cations by stable bonds with the negative radicals on the mineral surfaces is promoted by higher $\mathrm{pH}$ values. Zeolite minerals can play a significant role in thus surface complexion because of their high specific surface (Korkuna et al., 2006 and Sponer et al., 2001). The increase $\mathrm{pH}$ value of treated soil by the tested amendments (Table 2) confirmed the buffering effect (Radulescu, 2013) and suggested the opportunity of using zeolitic materials for conditioning and remedying contaminated soil from sulfide mines.

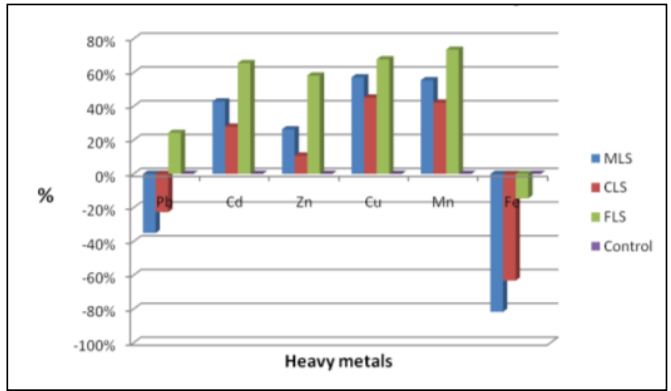

Figure 4 - The \% effect in the solubility of heavy metals in the different soil treatments.

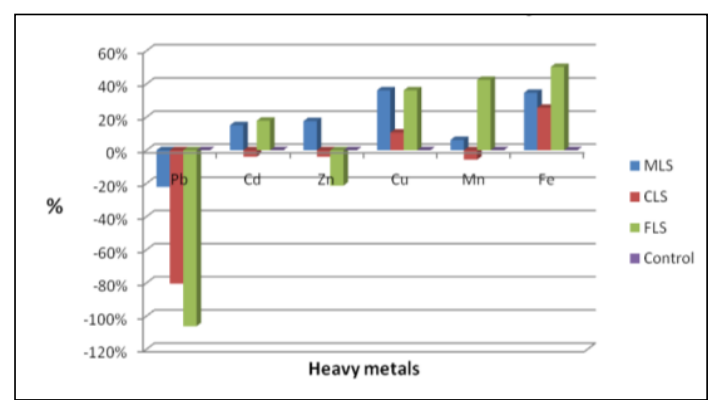

Figure 5 - The \% effect in potential bioavailability of heavy metals in the different soil treatments.

The effect of natural and synthetic zeolitic materials in potential bioavailability of studied heavy metals is displayed in Figure 5. The treatment with the synthetic material (FLS) exhibited the highest effectiveness in reduction of potential bioavailability of $\mathrm{Cd}, \mathrm{Cu}, \mathrm{Mn}$ and $\mathrm{Fe}$. The synthetic zeolitic material originated from the alkaline hydrothermal treatment of fly ash, resulted to a significant decrease of the contaminants leachability and potential bioavailability. The increase of $\mathrm{pH}$, as also indicated by Stouraiti et al. (2002) may be a key factor for the toxic elements immobilization. As regards the natural zeolites, mordenite proved to be more effective in controlling the potential bioavailability of all studied heavy metals except $\mathrm{Pb}$, in contrast to the clinoptilolite which presented a poor effect for almost all heavy metals. The potential bioavailability of $\mathrm{Pb}$ and $\mathrm{Zn}$ (Table 3) in the amended samples was higher in comparison to the untreated soil sample (Control). However, it is widely accepted that the EDTA test overestimates the bioavailable content of pollutants (Stouraiti et al., 2002).

The plant response to heavy metals in soil depends on the plant species, the total soil metal concentration, and the bioavailability of the metal (Martinez-Sanchez et al., 2012). For example, excluders have an avoidance (or restriction) mechanism which prevents element uptake, while 
accumulators have mechanisms of metal accumulation in their aboveground biomass (Perez-Sirvent $e t$ al., 2008). The bioconcentration factor (BCF), defined as the ratio of metal concentration in plant shoots to metal concentration in soil, is a measure of the ability of a plant to take up and transport metals to the shoots, which are the parts that can be easily harvested. With rare exceptions, most plants have a BCF for heavy metals and metalloids of less than 1 (McGrath and Zhao, 2003).

Glaucium flavum is a plant species that grows naturally in the contaminated fields of Lavrion, region. It is abundant along the roadsides and it is a short cycle plant. For all the studied elements, root concentrations were higher than those of shoots \& leaves as expected for most of the plant species. $\mathrm{BCF}$ in that plant was found lower than 1 (almost by two factors) for all the studied elements (Table 4). According to Martinez-Sanchez et al. (2012) Glaucium flavum is considered as a hypertolerant plant. Our findings suggest that Glaucium flavum does not accumulate high concentrations of metals and may inherit an avoidance/restriction mechanism that not only prevents all the studied toxic elements uptake but tolerates the low soil $\mathrm{pH}$ of the acid mine soil. Hence the presence of bioavailable trace elements in soils is not a critical factor that controls the uptake ability of the plants. It is therefore suggested the implementation of such measurements on specific plant species, in order to avoid misleading results that might influence the farming activity.

\section{Conclusions}

The synthetic zeolitic material originated from alkaline hydrothermal treatment of fly ash, resulted in a significant decrease of contaminants leachability and potential bioavailability. The $\mathrm{pH}$ increase of the amended soil confirmed the buffering effect of the zeolitic materials, along with the reduction of the heavy metals mobility, indicating their possible use in conditioning and remediating mining soils. The zeolite produced by Meliti's lignite fly ash was the most effective among the tested amendments. Our results suggest that those low temperature synthetic zeolites are suitable for in situ de-contamination of mining soils. Comparing the natural zeolitic materials from Samos Island, mordenite-rich tuff proved to be the most efficient at reducing the potential bioavailability of almo st all the heavy metals studied. The need for a low-cost amendment for the in-situ remediation of Lavrion mine degraded soils, may be effectively fulfilled with a large scale use of zeolitic materials. The plant species Glaucium flavum does not accumulate high concentrations of metals, exhibiting an avoidance/restriction mechanism that prevents the uptake of all the studied toxic elements from the contaminated soil.

\section{Acknowledgements}

University of Athens (NKUA) is acknowledged for the support of this work. The RFCS of the European Commission is thanked for funding a part of this research [Research Project MANAGER (Management of mine water discharges to mitigate environmental risks for post-mining period-RFCRCT-2013-00005)]. Dr. Pinelopi Delipetrou, Department of Botany, NKUA is kindly thanked for the identification of the plant specimens. Mrs Stefania Stamataki, chemist is thanked for language editing.

\section{References}

Adriano, D.C., Wenzel, W.W., Vangronsveld, J. and Bolan, N.S., 2004. Role of assisted natural remediation in environmental cleanup, Geoderma, 122, 121-142.

Alexopoulos, D., Itskos, G., Vasilatos, Ch., Koukouzas N. and Stamatakis, M.G., 2013. Mine wastewater treatment by highly calcareous and siliceous fly ash: a comparative study. World of Coal Ash Conference, Lexington, Kentucky, April 2013.

Baker, A.J.M., McGrath, S.P., Sidoli, C.M.D. and Reeves, R.D., 1994. The possibility of in situ heavy-metal decontamination of polluted soils using crops of metal accumulating plants, Resources Conservation Recycling, 11, 41-49.

Basaldella, E.I., Vazquez, P.G., Iucolano, F. and Caputo, D., 2007. Chromium removal from water using LTA zeolites: effect of pH, J. Colloid Interface Sci., 313, 574-578. 
Boisson, J., Mench, M., Vangronsveld, J., Ruttens, A., Kopponen, P. and Koe, T., 1999. Immobilization of trace metals and arsenic by different soil additives: evaluation by means of chemical extractions, Commun. Soil Sci. Plant Anal., 30, 365-387.

Breck, D.W., 1974. Zeolite Molecular Sieves: Structure, Chemistry and Use, New York, John Wiley and Sons Press.

Cardoso, A.M., Paprocki, A., Ferret, L.S., Azevedo, C.M.N. and Pires, M., 2015. Synthesis of zeolite Na-P1 under mild conditions using Brazilian coal fly ash and its application in wastewater treatment, Fuel, 139, 59-67.

Castaldi, P., Santona, L. and Melis, P., 2005. Heavy metal immobilization by chemical amendments in a polluted soil and influence on white lupin growth, Chemosphere, 60, 365-371.

Chen, Z.S., Lee, G.J. and Liu, J.C., 2000. The effects of chemical remediation treatments on the extractability and speciation of cadmium and lead in contaminated soils, Chemosphere, 41, 235-242.

Chlopecka, A. and Adriano, D.C., 1997. Influence of zeolite, apatite and Fe-oxide on $\mathrm{Cd}$ and $\mathrm{Pb}$ uptake by crops, Sci. Total Environ., 207, 195-206.

Conner, J.R., 1990. Chemical Fixation and Solidification of Hazardous Wastes, Van Nostrad Reinhold, New York, 692 pp.

Filippidis, A., 2010. Environmental, industrial and agricultural applications of Hellenic Natural Zeolite, Hellenic Journal of Geosciences, 45, 91-100.

Filippidis, A., Kantiranis, N., Stamatakis, M., Drakoulis, A. and Tzamos, E., 2007. The cation exchange capacity of the Greek zeolitic rocks. Bulletin of the Geological Society of Greece, 40, 723-735, Proceedings of the 11 $1^{\text {th }}$ International Congress, Athens, May, 2007.

Filippidis, A. and Kantiranis, N., 2005. Industrial, agricultural and environmental uses of the natural zeolites of Thrace, Bull. Geol. Soc. Greece, 37, 90-101.

Giannatou, S., Vasilatos, Ch., Mitsis, I. and Koukouzas, N., 2015. Use of natural and synthetic zeolitic materials as soil amendments in abandoned mine sites. In: Stamatakis, M.G., eds., Coastal Landscapes, Mining Acitivities and Preservation of Cultural Heritage, Cambridge Scholars Publishing.

Ha, N.T.H., Sakakibara, M., Sano, S. and Nhuan, M.T., 2011. Uptake of metals and metalloids by plants growing in a lead-zinc mine area, Northern Vietnam, Journal of Hazardous Materials, 186, 1384-1391.

Itskos, G., Koukouzas, N., Vasilatos, Ch., Megremi, I. and Moutsatsou, A., 2010. Comparative uptake study of toxic elements from aqueous media by the different particle-size-fractions of fly ash, Journal of Hazardous Materials, 183, 787-792.

Itskos, G., Koutsianos, A., Koukouzas, N. and Vasilatos, Ch., 2015. Zeolite development from fly ash and utilization in lignite mine-water treatment, Journal of Mineral Processing, 139, 4350, doi: 10.1016/j.minpro.2015.04.011.

Janos, P., Buchtova, H. and Ryznarova, M., 2003. Sorption of dyes from aqueous solutions onto fly ash, Water Res., 37, 4938-4944.

Karagozoglu, B., Tasdemir, M., Demirbas, E. and Kobya, M., 2007. The adsorption of basic dye (Astrazon Blue FGRL) from aqueous solutions onto sepiolite, fly ash and apricot shell activated carbon: kinetic and equilibrium studies, J. Hazard Mater., 147, 297-306.

Korkuna, O., Leboda, R., Skubiszewska-Ziemba, J., Vlublevska, T., Gunko, V.M. and Ryczkowski, J., 2006. Structural and physicochemical properties of natural zeolites: clinoptilolite and mordenite, Microporous Mesoporous Mater., 87, 243.

Koukouzas, N., Vasilatos, Ch., Itskos, G., Mitsis, I. and Moutsatsou, A., 2010. Removal of heavy metals from wastewater using CFB-coal fly ash zeolitic materials, Journal of Hazardous Materials, 173, 581-588.

Kumpiene, J., Lagerkvist, A. and Maurice, C., 2008. Stabilization of As, $\mathrm{Cr}, \mathrm{Cu}, \mathrm{Pb}$ and $\mathrm{Zn}$ in soil using amendments - a review, Waste Manage., 28, 215-225.

McGrath, S.P. and Zhao, F.J., 2003. Phytoextraction of metals and metalloids from contaminated soils, Current Opinion in Biotechnology, 14, 1-6.

Mansouri, N., Rikhtegar, N., Panahi, H.A., Atabi, F. and Shahraki, K.B., 2013. Porosity, characterization and structural properties of natural zeolite-clinoptilolite-as a sorbent, Environment Protection Engineering, 39, doi: 10.5277/EPE130111. 
Martinez-Sanchez, M.J., Garcia-Lorenzo, M.L., Perez-Sirvent, C. and Bech, J., 2012. Trace element accumulation in plants from an aridic area affected by mining activities, Journal of Geochemical Exploration, 123, 8-12.

Martinez-Sanchez, M.J., Martinez-Lopez, M.L., Garcia-Lorenzo, L.B., Martinez-Martinez, C. and PerezSirvent, C., 2011. Evaluation of arsenic in soils and plant uptake using various chemical extraction methods in soils affected by old mining activities, Geoderma, 160, 535-541.

Mouhtaris, Th., Charistos, D., Kantiranis, N., Filippidis, A., Kassoli-Fournaraki, A. and Tsirambidis, A., 2003. GIS-type zeolite synthesis from Greek lignite sulphocalcic fly ashes promoted by $\mathrm{NaOH}$ solutions, Microporous and Mesoporous Materials, 61, 57-67.

Pehlivan, E., Cetin, S. and Yanik, B.H., 2006. Equilibrium studies for the sorption of zinc and copper from aqueous solutions using sugar beet pulp and fly ash, J. Hazard Mater., B135, 193-199.

Peng, J.F., Song, Y.H., Yuan, P., Cui, X.Y. and Qiu, G.L., 2009. The remediation of heavy metals contaminated sediment, J. Hazard. Mater., 161, 633-640.

Perez-Sirvent, C., Martinez-Sanchez, M.J., Garcia-Lorenzo, M.L. and Bech, J., 2008. Uptake of Cd and $\mathrm{Pb}$ by natural vegetation in soils polluted by mining activities, Fresenius Environmental Bulletin, 17, 106.

Querol, X., Moreno, N., Umana, J.C., Alastuey, A. and Hermandez, E., 2002. Synthesis of zeolites from fly ash: an overview, J. Coal Geol., 50, 413-423.

Radulescu, H., 2013. Soil treatment effects of zeolitic volcanic tuff on soil fertility, Research Journal of Agricultural Science, 45(2).

Remenarova, L., Pipiska, M., Florkova, E., Hornik, M., Rozloznik, M. and Augustin, J., 2014. Zeolites from Coal Fly Ash as efficient Sorbents for cadmium ions, CleanTechn Environ Policy, Berlin, Heidelberg, Springer-Verlag, doi: 10.1007/s10098-014-0728-5.

Savvas, D., Samantouros, K., Paralemos, D., Vlachakos, G., Stamatakis, M.G. and Vassilatos, Ch., 2004. Yield and nutrient status in the root environment of tomatoes (Lycopersicon esculentum) grown on chemically active and inactive inorganic substrates, Acta Hortic., 644, 377-383.

Shi, W.Y., Shao, H.B., Li, H., Shao, M.A. and Du, S., 2009. Progress in the remediation of hazardous heavy metal-polluted soils by natural zeolite, Journal of Hazardous Materials, 170(1), 1-6.

Sponer, J.E., Sobalik, Z., Leszczynski, J. and Wicthterlova, B., 2001. Effect of metal coordination on the charge distribution over the cation binding sites of zeolites: A combined experimental and theoretical study, J. Phys. Chem., B105, 8285-8290.

Spurny, K.R., 1983. Natural fibrous zeolites and their carcinogenicity - a review, The Science of the Total Environment, 30, 147-166.

Sprynskyy, M., Golembiewski, R., Trykowski, G. and Buszewski, B., 2010. Heterogeneity and hierarchy of clinoptilolite porosity, J. Phys. Chem. Solids., 71, 1269.

Srivastava, V.C., Mall, I.D. and Mishra, I.M., 2006. Equilibrium modeling of single and binary adsorption of cadmium and nickel onto bagasse fly ash, Chem. Eng. J., 117, 79-91.

Stamatakis, M.G., Koukouzas, N., Vassilatos, C., Kamenou, E. and Samantouros, K., 2001. The zeolites from Evros region, Northern Greece: A potential use as cultivation substrate in hydroponics, Acta Hortic., 548, 93-104.

Stouraiti, C., Xenidis, A. and Paspaliaris, I., 2002. Reduction of $\mathrm{Pb}, \mathrm{Zn}$ and $\mathrm{Cd}$ availability from tailings and contaminated soils by the application of lignite fly ash, Water, Air and Soil Pollution, 137, 247-265.

Sun, D., Zhang, X., Wu, Y. and Liu, X., 2010. Adsorption of anionic dyes from aqueous solution on fly ash, J. Hazard. Mater., 181, 335-342.

Sunarso, J. and Ismadji, S., 2009. Decontamination of hazardous substances from solid matrices and liquids using supercritical fluids extraction: a review, J. Hazard. Mater., 161, 1-20.

Suzuki, Y., 1982. Carcinogenic and fibrogenic effects of zeolites: Preliminary observations, Environmental Research, 27, 433-445.

Vasilatos, C., Koukouzas, N. and Alexopoulos, D., 2015. Geochemical Control of Acid Mine Drainage in Abandoned Mines: The Case of Ermioni Mine, Greece, Procedia Earth and Planetary Science, 15, 945-950. 